\title{
First Measurements of a Monitoring project on a BTES system
}

\section{Patricia Monzó}

\author{
Alberto Lazzarotto
}

\author{
José Acuña
}

\begin{abstract}
Performance of Borehole Thermal Energy Storage (BTES) systems depends on the temperature of the secondary fluid, circulating through the ground-loop heat exchangers. Borehole systems are therefore designed in order to ensure that inlet and outlet temperatures of the secondary fluid are within given operational limits during the whole life-time of the system. Monitoring the operation of the bore fields is crucial for the validation of existing models utilized for their design. Measured data provides valuable information for researchers and practitioners working in the field. A first data-set from an ongoing monitoring project is presented in this article. The monitoring system comprises temperature sensors and power meters placed at strategic locations within the bore field. A distributed temperature sensing rig that employs fiber optic cables as linear sensors is utilized to measure temperature every meter along the depth of nine monitored boreholes, yielding data regarding both temporal and spatial variation of the temperature in the ground. The heat exchanged with the ground is also measured via power meters in all nine monitored boreholes as well as at the manifold level. The BTES system is located at the Stockholm University Campus, Sweden, and consists of 130 boreholes, 230 meters deep. After more than a year of planning and installation work, some selected measurements recorded in the BTES during the first months of operation are reported in this article.
\end{abstract}

\section{INTRODUCTION}

BTES systems actively and intentionally create an underground heat (and/or cold) store by means of a number of closed-loop borehole heat exchangers (BHEs) that use the surrounding rock or soil as a storage medium. As the heat carrier fluid circulates through the BHEs, heat is transferred, mainly by conduction, from the fluid to the surrounding ground and vice versa. The annual mean temperature of the ground storage volume varies according to the net heat that is exchanged over a year.

Performance of BTES systems depends on temperatures of the secondary fluid circulating in BHEs, which should be kept within a certain temperature range during the life of the system. Because the rate of year-to-year temperature increase or decrease levels out during the first years of operation, a life of 20-25 years is often assumed for the design calculation, even though the ground heat exchangers are expected to last much longer. To ensure the secondary fluid temperature to be within the operational temperature limits, BTES systems require accurate design tools to predict the long-term thermal response of the bore field over its life time.

Measured data of large bore fields is lacking in the academy. Mostly the response of small scale experimental setups (Acuña, 2013, Luo et al., 2013, Cimmino and Bernier, 2015) have been published. Data from in-situ monitoring of full scale installations (Hern, 2004, Montagud et al., 2011, Naiker and Rees, 2011, Sanner et al., 2016) are of a great value for validation of the methods implemented in bore field design tools. During the last years, the interest from industrial actors has resulted in a better understanding of the thermal response of bore fields. Examples where monitoring of bore fields is discussed are presented in (Mikhaylova et al., 2015, Michalski et al., 2016). Examples of validation of methods and design tools against measured data are illustrated in (Cullin et al., 2015, Sanner et al., 2016). Monitored data is also 
used to evaluate system performance and to investigate optimization schemes. Further developments of accurate bore field design tools, where aspects such as thermal interaction between neighboring boreholes, neighboring bore fields, influence of groundwater flow, and influence of other surrounded heat sources, may be strongly supported by accurate monitoring data of bore fields for long-term periods.

In this paper, a few data sets from an ongoing monitoring project on a new BTES installation are reported. The installation started operating on April, 15 2016. The measurements are presented for a two weeks period from September 2016. The monitoring system used consists of temperature sensors and power meters located at strategic positions within a bore field, as described in (Monzó et al., 2016). The work reported in this paper is one of the initial steps of a project that intends to evaluate and optimize the actual performance of the BTES system and use the measured data for validation of some bore field modelling approaches.

\section{DESCRIPTION OF THE BTES}

The BTES installation is designed to provide annually about $4 \mathrm{GWh}$ of cooling and about $3 \mathrm{GWh}$ of heating for one newly constructed building and for a group of existing buildings at Stockholm University Campus, Sweden. As described in (Monzó et al., 2016), the BTES is connected to a cluster of heating and cooling systems. In the summer, the heat rejected by two large chillers is stored in the ground. In the winter, space heating is provided partly by the heat rejected from the chillers and is partly supplied from the ground using a heat pump. During mild seasons, cooling is achieved from the BTES, and represents a minor portion of the total cooling demand. The BTES is sized to keep the temperature of the secondary fluid entering the heat pumps between $2.5^{\circ} \mathrm{C}$ and $31^{\circ} \mathrm{C}$. The secondary fluid is an aqueous solution of bioethanol ( $20 \%$ by weight). The BTES system operational power limits are $1400 \mathrm{~kW}$ for heat extraction and $2500 \mathrm{~kW}$ heat injection. Supplementary heating from a district-heating network is used when hourly peaks exceed the design limits. Dry cooler units are used when hourly peaks exceed design limits for cooling loads. The annual net design heat exchanged in the underground storage volume is around $1400 \mathrm{MWh}$ of cooling.

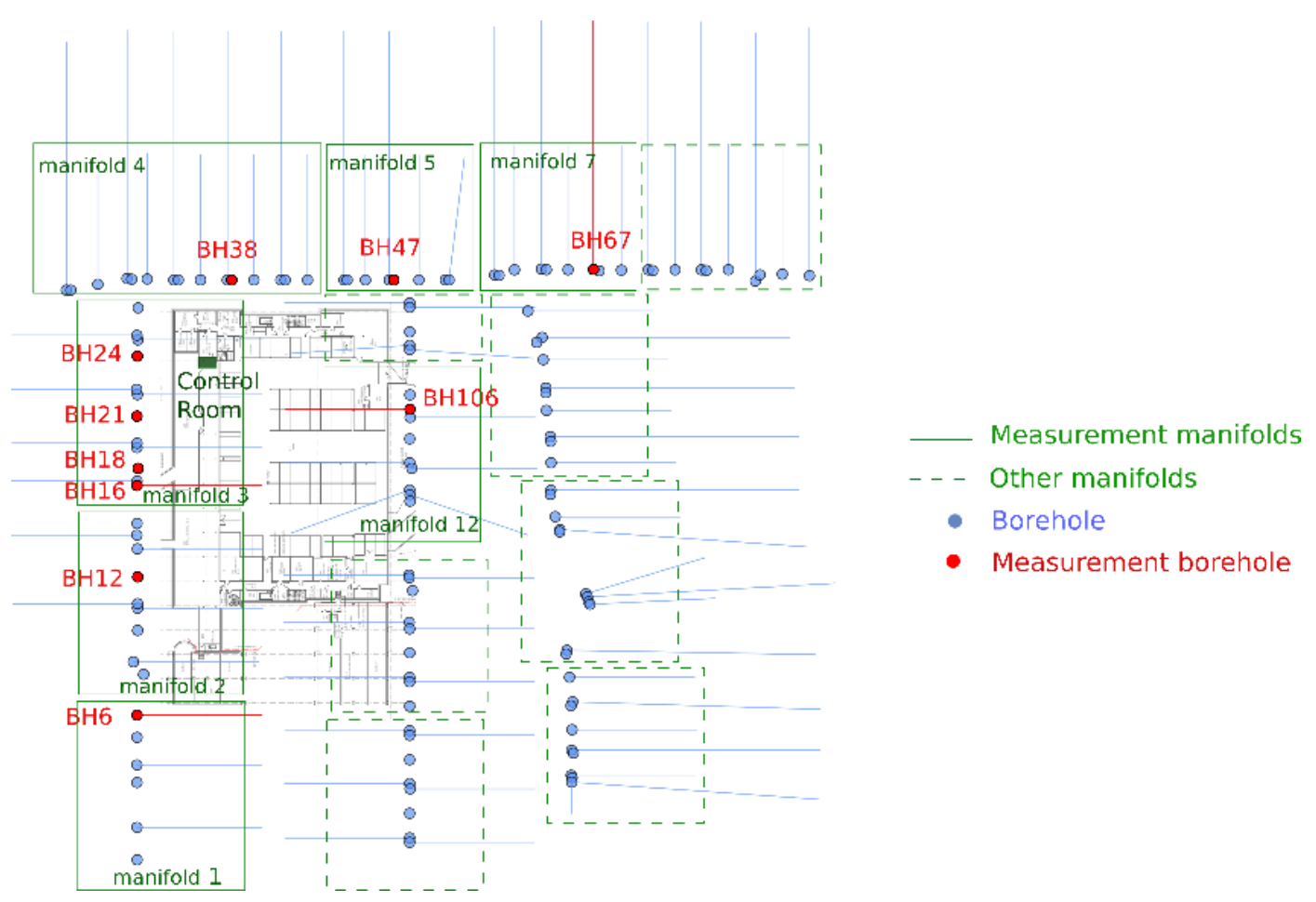

Figure 1 Plan view of the BTES - Bore field layout. 
The BTES system comprises 130 vertical and inclined groundwater filled BHEs, of 230 meter length, arranged in an uneven pattern that covers a total storage volume of around 5,850,000 $\mathrm{m}^{3}$. The ground thermal conductivity reported during the design phase is around $3.9 \mathrm{~W} /(\mathrm{m} \mathrm{K})$ with a volumetric heat capacity of the soil of around 2.2 $\mathrm{MJ} /\left(\mathrm{m}^{3} \mathrm{~K}\right)$. A storage ground capacity of around 3,570 MWh/K is obtained for the above mentioned storage volume. Thus, the expected temperature change in the storage volume due to the net annual heat exchanged (1400 MWh) over the first year is around $0.4 \mathrm{~K}$. Figure 1 illustrates the layout of the bore field and the arrangement of the boreholes within their corresponding manifolds. Manifolds illustrated with solid green lines represent measurement manifolds containing monitored boreholes. The position of monitored boreholes within the field is depicted by red circles in Figure 1. The projection of the inclined boreholes on the ground surface is also illustrated in Figure 1 using solid lines.

\section{MONITORING SYSTEM}

The monitoring system consists of power and temperature measurements. Power meters measure the volume flow $(1 / \mathrm{s})$ and fluid temperatures $\left({ }^{\circ} \mathrm{C}\right)$ at the supply and the return pipes, which corresponds to one set of measurement, in both measurement boreholes and their corresponding manifold. For further information about their and location within the bore field, readers are referred to (Monzó et al., 2016). The power meters are of type Dynaflox DEM-serie meters, with a pressure loss less than $0.02 \mathrm{MPa}$ at a permanent flow. The working temperature range is between $-5^{\circ} \mathrm{C}$ and $+95^{\circ} \mathrm{C}$. Two PT1000 resistance thermometers with precision of $\pm 0.1 \mathrm{~K}$ (according to manufacturer) are used to measure temperatures in the supply and return pipes. Power is measured every minute.

A distributed temperature sensing (DTS) instrument (type ORYX DTS) measure the temperature along optical fiber cables placed in the groundwater within the boreholes. The physical principle behind this measurement technique is based on the fact that glass fibers are sensitive to temperature changes. In DTS instrument a laser beam is sent through a fiber cable and the backscattered signal is collected and translated to temperature. The DTS instrument measures averages of temperature in both time and space. In our installation temporal sampling is set at 10 minutes interval and spatial sampling is set at 1 meter. The longest fiber cable loop installed at this site is about $3.5 \mathrm{~km} \mathrm{long}$. With this setting, a temperature resolution less than $0.1^{\circ} \mathrm{C}$ can be achieved according to the instrument manufacturer. The instrument has a single laser and four channels through which it is connected to the fiber cables. The laser is only active on one channel at a time, therefore an average temperature value for every meter of fiber cable is recorded every 40 minutes in each channel. For practical reasons, fiber cables are installed separately in each borehole (upward and downward). Since the DTS instrument requires a continuous fiber cable, fiber cables are spliced (welded) to achieve the arrangement in each DTS channel as shown in Table 1.

Table 1. Arrangement of measurement boreholes in each DTS channel

\begin{tabular}{cccc}
\hline Channel & Manifold & Borehole & $\begin{array}{c}\text { Total fiber cable } \\
\text { length[m] }\end{array}$ \\
\hline \hline 1 & $12-5-7$ & $106-47-62$ & 3300 \\
2 & 4 & 38 & 700 \\
3 & $2-1$ & $12-6$ & 2600 \\
4 & 3 & $21-16-18$ & 3500 \\
\hline
\end{tabular}

Figure 2 shows, as an example, the splice-fiber scheme and the temperature measurement recorded on 2016-0701 17:45:14 along the length of the fiber cable connected to channel 3. As presented in Table 1, two measurement boreholes in two manifolds are measured in channel 3. The fiber optic cable is installed so that the laser travels upwards and downwards in borehole 6 and 12 (outside the pipes). Each cable has four fibers, but only two of them are used in the set-up described in this paper, fiber 1 and 2 illustrated in Figure 2(a). The fibers are spliced so that the cables relative to the measurement boreholes are connected in series. This takes place at junction boxes 2 to 5 in the example shown in Figure 2, while fibers 1 and 2 connect to each other in junction box 1 (end-loop splice). This fiber set-up is also known as duplex arrangement (Hausner et al., 2011). Temperatures are measured twice along the cable. 
A post-processing step is necessary to identify the DTS measurements relative to the length of the fiber cables corresponding to each measurement borehole in each channel. The intervals of interest are identified by knowing the fiber cable path of the channel and by using some sections of the cable for reference. These sections are some extra meters of fiber cable reserved before and after the junction boxes, which serve as references when placed in thermal baths with a known temperature. In Figure 2(b), the length of the fiber cable corresponding to borehole 6 and 12 are highlighted along with the sections used as reference.
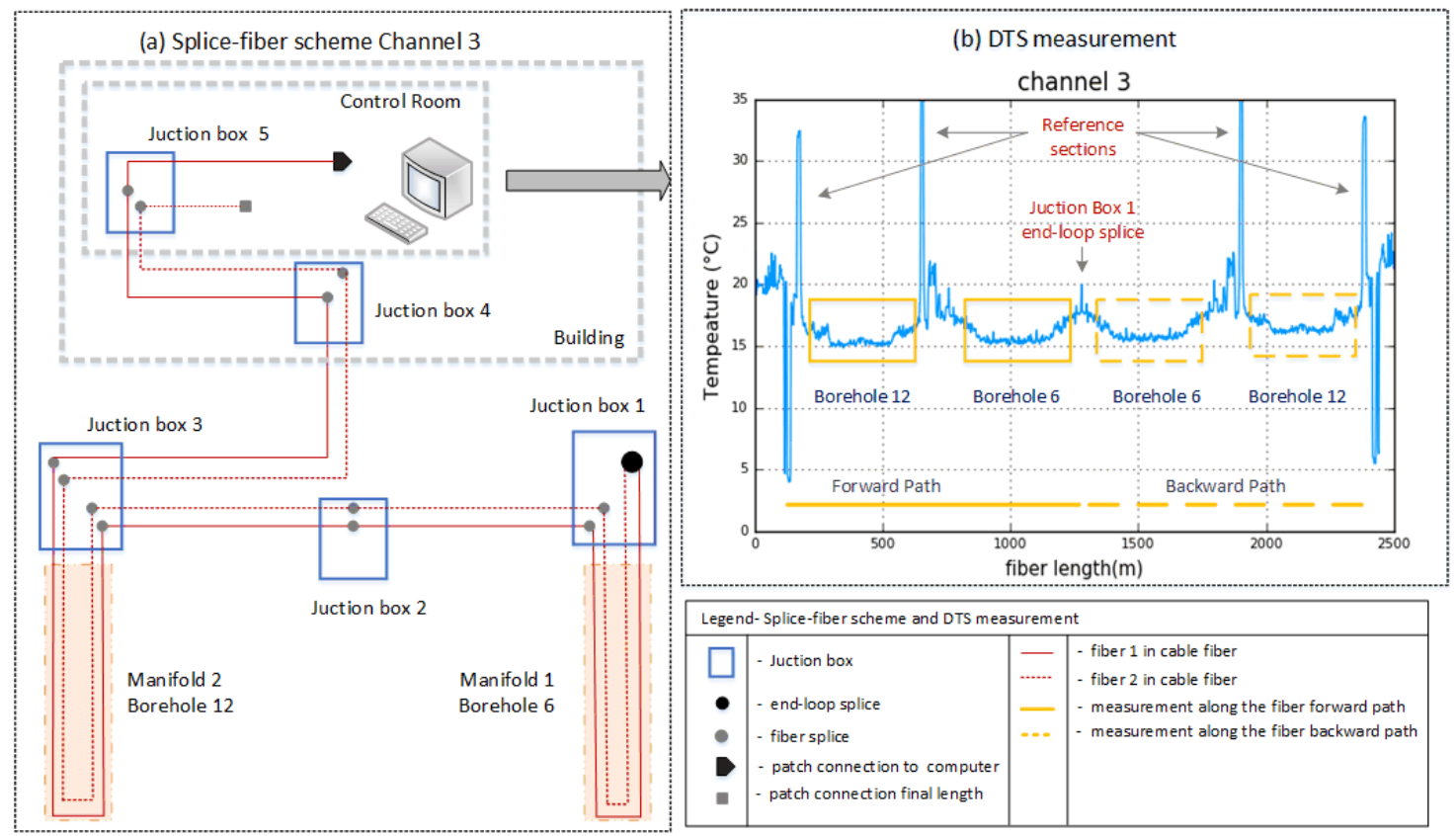

Figure 2 (a) Splice-fiber scheme in channel 3 in DTS equipment and (b) DTS measurements in channel 3 (during calibration test).

In December 2015 the fiber cables were connected to the DTS equipment. Subsequently, the DTS equipment was connected to a local data acquisition system and data has been recorded since then. During the connection of the fiber cables to the DTS equipment, we realized that the fiber cable in one of the selected boreholes, borehole 24 in manifold 4, was not transmitting. The fiber cable probably broke during the construction work at the site. Currently, the temperature along the depth of 9 of the 10 instrumented boreholes is monitored. The connection of the power meters to a local data acquisition system was accomplished in June 2016 and since then power data is being recorded. Because of flooding of one measurement well where power meters are placed, the meters relative to borehole 6 and manifold 1 were damaged and they do not transmit accurate values at the moment. Unexpected low measurements of volume flow rates were observed in borehole 38, which are not reported in this paper. The power meters use an M-bus connection to transfer the data while the DTS unit communicates through a serial connection.

Once the data acquisition system was set up, a careful mapping of the instruments was carried out. The raw power data received through the local data acquisition system (one set of measurements for each power meter) were not initially tagged and manual identification was required to map the measurement to the relative meter. For this purpose, advantage was taken of the fact that boreholes and manifolds are equipped with flow control valves and are labelled at the site according to the numbering presented in (Monzó et al., 2016). The mapping process consisted of closing the flow control valve of each of the measurement boreholes and manifolds, one at a time. For each of these time intervals one set of measurement recorded by our data acquisition system returned a zero value for the volume flow, indicating the correspondence between data and the relative meter. This procedure allowed the identification and tagging of each set of power measurements. Mapping of the DTS measurements required both the identification of the specific 
boreholes connected in each channel and the section of the fiber cable relative to each borehole. The monitored boreholes were closed, one by one, for periods of about 10 hours, so that no heat was injected in the closed boreholes. During these time spans, the measured temperature profiles along the borehole length showed that one of the temperature profile had a distinct behavior compared to the others enabling the identification of the boreholes in each channel. The mapping of the sections of interest in the fiber cables was done as previously exemplified for channel 3.

\section{FIRST MEASUREMENTS}

After performing some operational tests during February and March 2016, the BTES system started its operation on April 152016 with a total heat injection of around 3400 MWh since then. Since the monitoring set-up was fully operational in September 2016, the authors have chosen a two weeks period from September 2016 to be reported in this paper.

\section{Power Measurements}

Measurements of volume flows $\dot{V}(\mathrm{l} / \mathrm{s})$ and temperatures $\left({ }^{\circ} \mathrm{C}\right)$ at the supply, $T_{\text {in }}$, and return pipes, $T_{\text {out }}$, are obtained from the power meters installed in measurement manifolds and boreholes. The power $q(\mathrm{~W})$ exchanged in the pipe loop results from $q=\dot{V} \cdot \rho \cdot C_{p} \cdot\left(T_{\text {in }}-T_{\text {out }}\right)$. The density, $\rho\left(\mathrm{kg} / \mathrm{m}^{3}\right)$, and the specific heat capacity, $C_{p}(\mathrm{~J} /(\mathrm{kg} \mathrm{K})$ of the secondary fluid at the working temperature is calculated continuously using analytical correlations from experimental measurements presented in (Ignatowicz et al., 2016).

Figure 3 shows examples of the volume flow, inlet and outlet temperatures and power measured at the monitored manifolds from Sept 8 to Sept 21. Figure 4 presents measurements at the borehole level. The period shown in Figure 3 and 4 corresponds to a heat injection period. Two operation strategies related to the outdoor temperatures can be distinguished in Figure 3 and Figure 4. "Strategy 1" from Sept 8 to Sept 15 characterized by large heat injection when the average daily temperature is around $17.5^{\circ} \mathrm{C}$, and "Strategy 2 " from Sept 16 to Sept 21 when the average outdoor daily temperature was lower $\left(13.3^{\circ} \mathrm{C}\right)$ and less heat was injected into the ground. On a daily basis, two operation schemes can also be observed: a "day time scheme" and a "night time scheme". The former occurs approximately from 8 am to $9 \mathrm{pm}$ when buildings are occupied and outdoor temperatures are higher. The latter occurs approximately from 9 pm to $8 \mathrm{am}$, when there is no building occupancy and outdoor temperatures are lower. Slightly less heat is injected into the BTES during weekends (especially at nights), since the decreased occupancy of the buildings reduces the demand of cooling loads.

During the "day time scheme" between Sept 8 to Sept 15, a fluid temperature difference of 3 to $4 \mathrm{~K}$ is maintained, and the capacity of the system is adjusted by changing the volume flow. In the "night time scheme" the temperature difference decreases to values around 1.5 to $2 \mathrm{~K}$ and the volume flow is kept at its minimum rate. In Strategy 2 (Sept 16 to Sept 21), during "day time scheme", the fluid temperature difference is around $3 \mathrm{~K}$ and the volume flow is varied to satisfy the heat injection. While for the "night time scheme" the temperature difference is reduced to around $1 \mathrm{~K}$ and the volume flow is kept to its minimum rate. On Sept 19, a peak injection occurred during early hours of "day time scheme". The heat injection in the second period (Sept 16 to Sept 21) is reduced by around 30\% in comparison to the first period (Sept 8 and Sept 15). On a daily basis, the heat injected (in both observed periods) varies around 50\% between day time and night time schemes. It can also be observed that the heat injection into the BTES is softened from the intermittent on/off operation of chillers by means of a buffer tank that decouples the BTES from the remaining systems in the cluster, as shown in (Monzó et al., 2016).

Figure 3 also shows that the mass flow distribution among the manifolds has been balanced in order to have higher flow rates in manifolds with a larger number of boreholes. Similarly, the more boreholes per manifold, the larger amount of heat injected by manifold. When comparing inlet temperatures in manifolds at a given time, a maximum difference of around $1.5 \mathrm{~K}$ is observed at this reported period. Heat losses in piping between central pipe and measurement wells may partly explain the differences in inlet temperatures. The comparison of the outlet temperatures 
in the manifolds during this period also shows that the largest deviation is about $1.5 \mathrm{~K}$. The discrepancies in inlet and outlet temperatures are consistent. However, because of the relatively high inlet temperatures differences, further investigation will be carried out at site to pinpoint possible biases in the measurements.
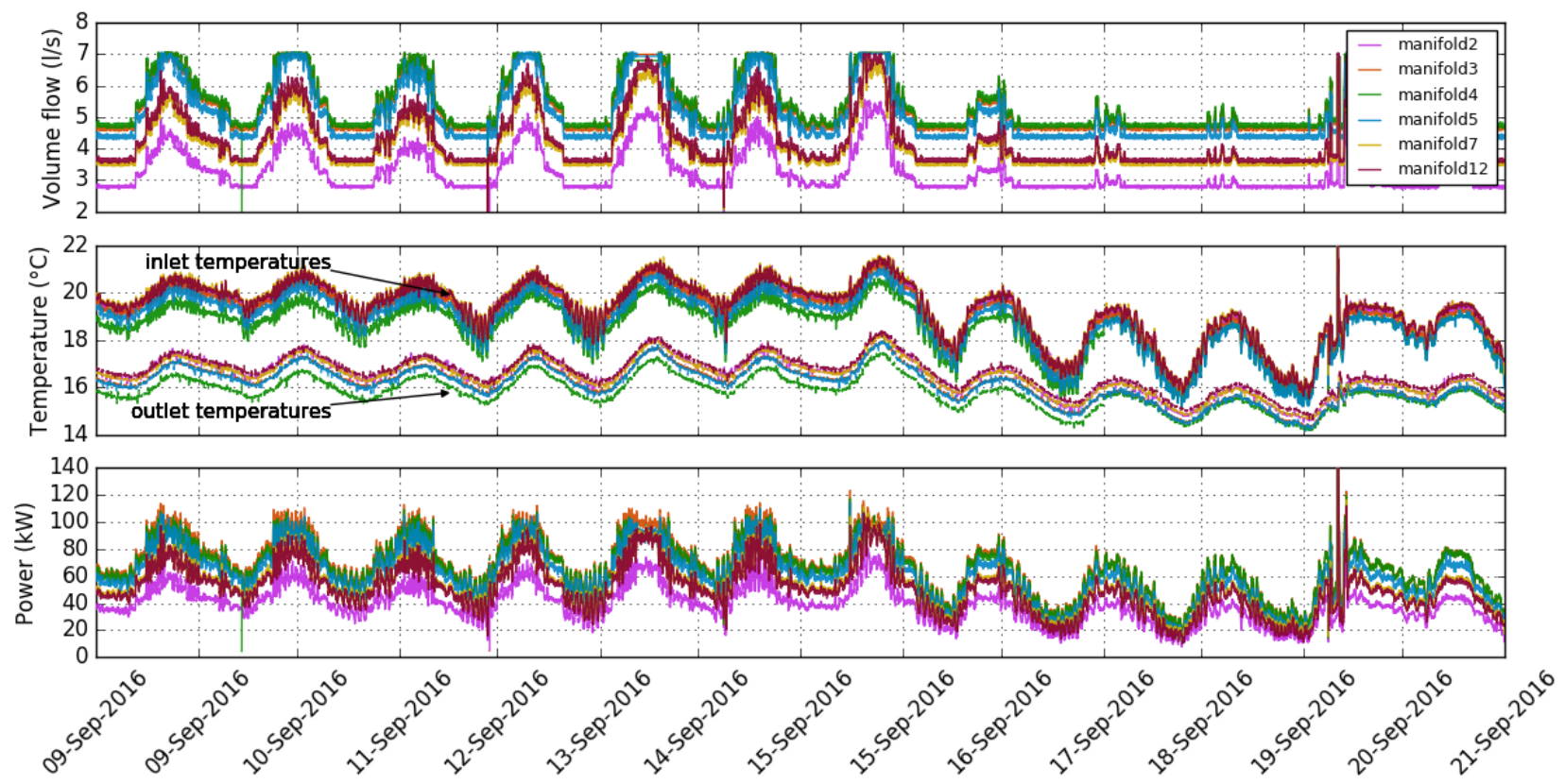

Figure 3 Volume flow, inlet and outlet temperatures and power at the measurement manifolds during Sept 8 to 21 .
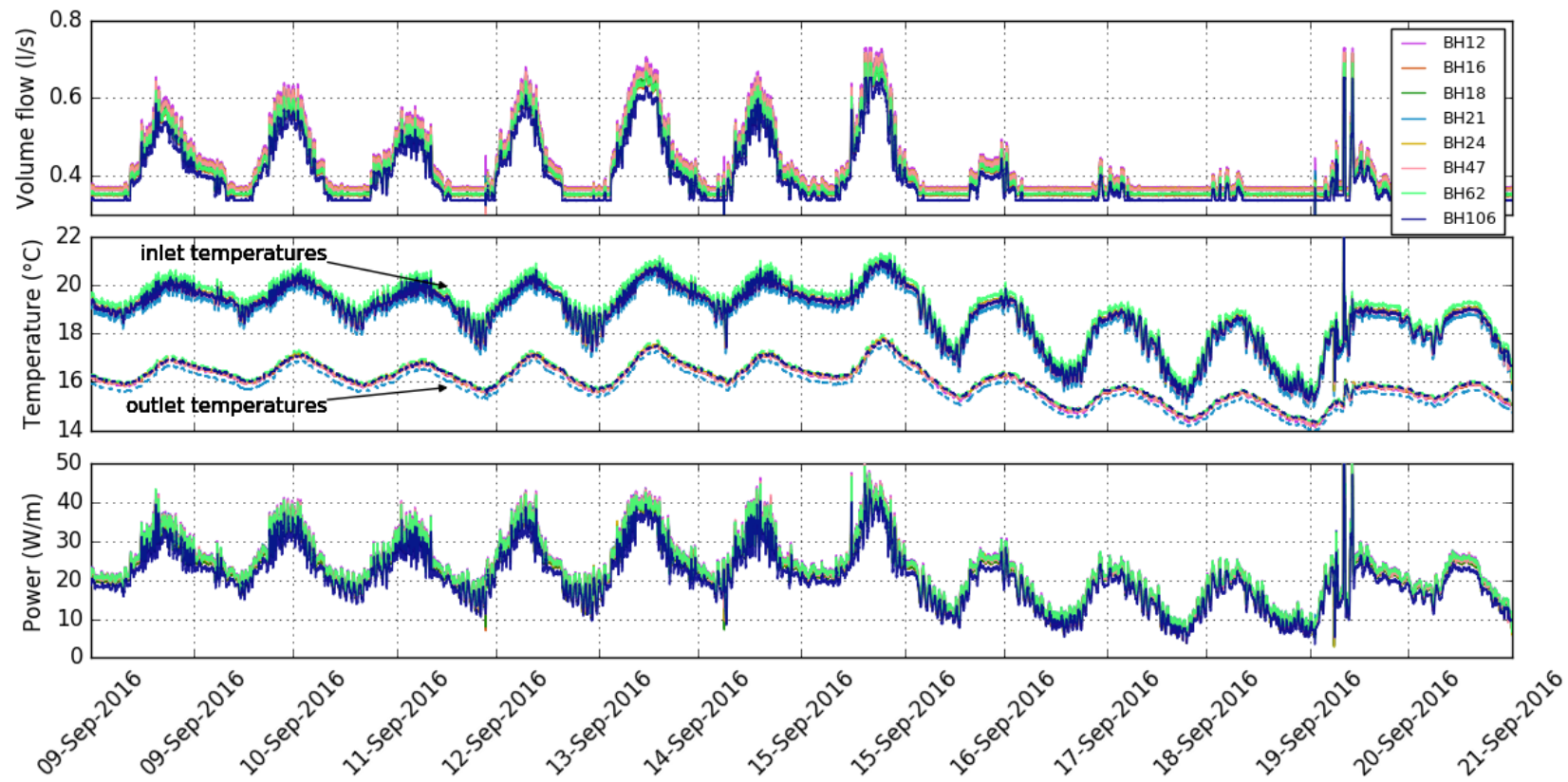

Figure 4 Volume flow, inlet and outlet temperatures and power at the measurement boreholes during Sept 8 to 21.

Measurements from power meters in monitored boreholes are shown in Figure 4, with the exception of borehole 6 and 38. Variation around $\pm 5 \%$ in volume flows is observed in the investigated period, which illustrates that the mass flow are relatively balanced among the boreholes. Due to the operational strategies applied, the volume flow per borehole varies approximately between 0.2 to $0.75 \mathrm{l} / \mathrm{s}$. For a secondary fluid temperature of $16^{\circ} \mathrm{C}$, a fluid to pipe thermal 
resistance of 0.02 to $0.0051(\mathrm{~m} \mathrm{~K}) / \mathrm{W}$ results for this range of observed flow rates. Temperature differences between the fluid and the borehole wall change by about 0.15 degrees for the heat injection $(20$ to $50 \mathrm{~W} / \mathrm{m})$ occurring during the reported period. This change in the volume flow influences the thermal and the hydraulic performance of the borehole. Further investigation to assess the benefit of alternatives strategies will be performed in future work.

At any instant during this period, a maximum difference of $1.4 \mathrm{~K}$ is observed between inlet temperatures in measurement boreholes. A maximum difference between manifolds and boreholes of approximately $0.6 \mathrm{~K}$ is observed. Borehole inlet temperatures are expected to have a value similar to the inlet to their relative manifolds. Further examination at site will be devoted to amend these issues. The power injection per unit length $(\mathrm{W} / \mathrm{m})$ illustrates that the heat injection loads are balanced among the boreholes. The power is about the same in all monitored boreholes with exception of slightly lower values at borehole 106. The power injection per unit length $(\mathrm{W} / \mathrm{m})$ during the first period (Sept 8 and Sept 15) reaches values of around 40 to $50 \mathrm{~W} / \mathrm{m}$ for "day time scheme", while it decreases to 20 $\mathrm{W} / \mathrm{m}$ at "night time scheme". During the second period (Sept 16 and Sept 21), the power injection per unit length $(\mathrm{W} / \mathrm{m})$ is around $20 \mathrm{~W} / \mathrm{m}$ at "day time scheme" and around $5 \mathrm{~W} / \mathrm{m}$ at "nigh time scheme".

\section{Temperature Measurements}

Work on calibration of the DTS measurements is ongoing. Figure 5 shows raw data of the groundwater temperature measured along the length of the nine monitored boreholes at two specific time steps. The first time chosen occurs before the operation of the BTES was started, on February 1, 2016, while fluid circulation was taking place in all boreholes. The measurements show that the temperature of the groundwater outside the pipes tended to be evened out along the depth of all borehole. The second time is chosen on Sept 10, 2016, a moment when the groundwater temperature along the boreholes increases in comparison with the profiles observed in the first period. The latter reflects the effect of the injection of heat into BTES during the first cooling season, since April 15, 2016. It can be also observed that the increase is non uniform along the depth. The new profiles present a temperature difference of around $2 \mathrm{~K}$ between the top and the bottom of the boreholes. The upper part of the boreholes might be exchanging a larger share of heat than the bottom part. Temperatures discontinuities along the borehole depth are observed at a few sections, for instance at about $75 \mathrm{~m}$ in BH106. These local features will be analyzed in the near future.

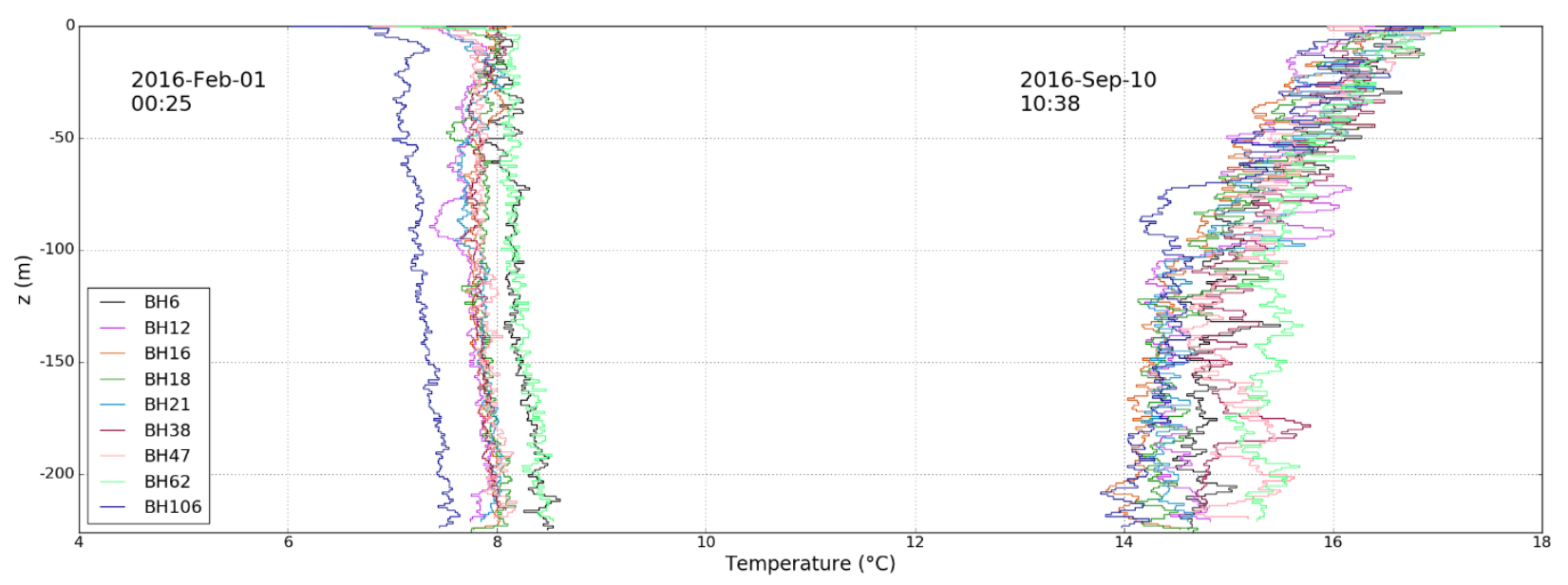

Figure 5 Temperature measurements along the borehole length at two particular times.

\section{CONCLUSION}

A monitoring set up and a few data sets from a BTES system, consisting of 130 groundwater filled BHEs, are presented in this paper. The BTES system started operating on April 15, 2016. Relevant activities related to the final implementation of the BTES monitoring set-up are described. The set-up comprises groundwater temperature 
measurements along the depth of nine selected monitored boreholes and power measurements at all monitored boreholes and at their relative manifolds.

The power measurements show large variation of volume flows in the ground loop, which might play a major role on regulation of the heat load to the BTES. Raw data regarding groundwater temperature along the depth of all the monitored boreholes is shown while circulating the secondary fluid before the operation of the BTES as well as during the end of the cooling season while injecting heat into the ground. At all boreholes, the groundwater temperature is evened out along the depth when only circulation occurs and increases during heat injection. A temperature difference of around $2 \mathrm{~K}$ from the top to the bottom of the borehole is observed. These first data sets show the potential of the described monitoring system and provides an insight into detailed information that will successively be published regarding how this BTES system is operated and how the temperatures within the BTES are affected in accordance with operational strategies. The work reported in this paper is one of the initial steps of a project that intends to evaluate and optimize the actual performance of the system and use the measured data for validation of some bore field modelling approaches.

\section{ACKNOWLEDGMENTS}

The Swedish Energy Agency and all industry partners: Hesselmannska stiftelsen, Akademiska Hus, Skanska, Tyréns and Stures Brunnsborrningar, are gratefully acknowledged for co-financing and helping on this project.

\section{REFERENCES}

Acuña, J., 2013. Distributed thermal response tests: New insights on U-pipe and Coaxial heat exchangers in groundwater-filled boreholes, PhD Thesis, Dep. of Energy Technology, Royal Institute of Technology, Sweden.

Cimmino, M., Bernier, M., 2015. Experimental determination of the g-functions of a small-scale geothermal borehole. Geothermics 56, 60-71.

Cullin, J.R., Spitler, J.D., Montagud, C., Ruiz-Calvo, F., Rees, S.J., Naicker, S.S., Konečný, P., Southard, L.E., 2015. Validation of vertical ground heat exchanger design methodologies. Sci. Technol. Built Environ. 21(2), 137-149.

Hausner, M.B., Suárez, F., Glander, K.E., Giesen, N. van de, Selker, J.S., Tyler, S.W., 2011. Calibrating Single-Ended Fiber-Optic Raman Spectra Distributed Temperature Sensing Data. Sensors 11, 10859-10879.

Hellström, G., 1991. Ground Heat Storage. Thermal Analyses of Duct Storage Systems, PhD Thesis, Dep. of Mathematical Physics, University of Lund, Sweden.

Hern, S.A., 2004. Design of an Experimental Facility for a Hybrid Ground Source Heat Pump, Master of Science, Oklahoma State University, Stillwater, Oklahoma.

Ignatowicz, M., Mazzotti, W., Acuña, J., Melinder, A., Palm, B., 2016. Alternative Alcohol blends as seondary fluids for ground source heat pumps, in: Proc. 12th IIIR Gustav Lorentzen Natural Working Fluids Conference, Scotland, UK.

Luo, J., Rohn, J., Bayer, M., Priess, A., 2013. Thermal Efficiency Comparison of Borehole Heat Exchangers with Different Drillhole Diameters. Energies 6, 4187-4206.

Michalski, A., Fütterer, J., Mottarghy, D., Norbet, K., 2016. Long-term performance of a borehole heat exchanger field connected to a multifunctional office building, in: Proc. European Geothermal Congress 2016. Strasbourg, France.

Mikhaylova, O., Johnston, I.W., Narsilio, G.A., Kivi, A.V., Aditya, R., Noonan, G., 2015. Performance of Borehole Ground Heat Exchangers under Thermal Loads from a School Building: Full-scale Experiment in Melbourne, in: Proc. World Geothermal Congress, Melbourne, Australia.

Montagud, C., Corberán, J.M., Montero, Á., Urchueguía, J.F., 2011. Analysis of the energy performance of a ground source heat pump system after five years of operation. Energy Build. 43, 3618-3626.

Monzó, P., Lazzarotto, A., Acuña, J., Tjernström, J., Nygren, M., 2016. Monitoring of a borehole thermal energy storage in Sweden, in: Proc. 12th REHVA World Congress CLIMA, Aalborg, Denmark, vol3.

Naiker, S.S., Rees, S.J., 2011. Monitoring and Performance Analysis of a Large Non-domestic Ground Source Heat Pump Installation. Presented at the CIBSE Technical Symposium, Leicester UK. 
Sanner, B., Bockelmann, F., Kühl, L., Mands, E., 2016. System optimisation of ground-coupled heat and-cold supply of office buildings, in: Proc. European Geothermal Congress 2016. Strasbourg, France. 